\title{
POLARIZATION STABILITY OF AMORPHOUS PIEZOELECTRIC POLYIMIDES
}

C. PARK*, Z. OUNAIES**, J. SU*, J.G. SMITH JR. AND J.S. HARRISON

Advanced Materials and Processing Branch, NASA Langley Research Center, Hampton VA, 23681-2199.

*National Research Council

**ICASE

\section{ABSTRACT}

Amorphous polyimides containing polar functional groups have been synthesized and investigated for potential use as high temperature piezoelectric sensors. The thermal stability of the piezoelectric effect of one polyimide was evaluated as a function of various curing and poling conditions under dynamic and static thermal stimuli. First, the polymer samples were thermally cycled under strain by systematically increasing the maximum temperature from $50^{\circ} \mathrm{C}$ to $200^{\circ} \mathrm{C}$ while the piezoelectric strain coefficient was being measured. Second, the samples were isothermally aged at an elevated temperature in air, and the isothermal decay of the remanent polarization was measured at room temperature as a function of time. Both conventional and corona poling methods were evaluated. This material exhibited good thermal stability of the piezoelectric properties up to $100^{\circ} \mathrm{C}$.

\section{INTRODUCTION}

Aromatic polyimides have been used in a wide variety of aerospace applications because of their chemical and radiation resistance, with excellent thermal, mechanical, and dielectric properties. Recently, a series of novel piezoelectric polyimides containing pendant, polar groups have been synthesized and evaluated at NASA-LaRC for potential use in micro-electro-mechanical systems (MEMS) devices [1,2]. The initial investigations have shown that they exhibited a piezoelectric response at temperatures in excess of $150^{\circ} \mathrm{C}$ [3].

Experimental studies of the thermal stability of a piezoelectric amorphous polyimide, $(\beta-$ $\mathrm{CN}) \mathrm{APB} / \mathrm{ODPA}$, are presented here as a function of various curing and poling conditions under dynamic and static thermal stimuli. Both conventional and corona poling methods were employed for this study. Corona poling was used to maximize the degree of dipolar orientation and minimize localized arcing during in-situ imidization and poling. The results of both poling methods are discussed.

\section{EXPERIMENTAL}

\section{Film preparation}

The polyimide evaluated was $(\beta-\mathrm{CN}) \mathrm{APB} / \mathrm{ODPA}$, which was prepared from 2,6-bis(3aminophenoxy) benzonitrile ( $(\beta-\mathrm{CN}) \mathrm{APB})$ and 4,4' oxidiphthalic anhydride (ODPA) via a polyamic acid solution in N,N-dimethylacetamide and subsequent thermal imidization. The synthesis was reported in detail elsewhere [3]. The polyamic acid solution was cast to form approximately $30 \mu \mathrm{m}$ thick films. The tack-free films were imidized under various cure cycles to produce samples having different degrees of imidization. The exact cure cycles are summarized in Table I. A silver layer, approximately $200 \mathrm{~nm}$ thick, was evaporated on both sides of the films for conventional poling and only one side of the films for corona poling. 
Table I. Processing parameters and properties of partially-cured, corona poled $(\beta-$ CN)APB/ODPA: cure cycle, $\mathrm{T}_{\mathrm{g}}$, degree of imidization $\left(\mathrm{A} 1780 \mathrm{~cm}^{-1 /} \mathrm{A} 1500 \mathrm{~cm}^{-1}\right)$, and $P_{r}$.

\begin{tabular}{clccc}
\hline Sample & \multicolumn{1}{c}{$\begin{array}{c}\text { Cure cycle }\left({ }^{\circ} \mathrm{C}\right) \\
1 \text { hour each, } \mathrm{N}_{2}\end{array}$} & $\begin{array}{c}\mathrm{T}_{\mathrm{g}} \text { before poling } \\
\left({ }^{\circ} \mathrm{C}\right)\end{array}$ & $\begin{array}{c}\mathrm{A} 1780 \mathrm{~cm}^{-1 /} \mathrm{A} 1500 \mathrm{~cm}^{-1} \\
\left(\mathrm{mC} / \mathrm{m}^{2}\right)\end{array}$ & $\begin{array}{c}P_{r} \\
\text { P100 }\end{array} 50,100$ \\
P150 & 50,150 & 142 & 0.18 & N/A \\
P200 & $50,150,200$ & 166 & 0.69 & 26 \\
P240 & $50,150,200,240$ & 218 & 0.82 & 9 \\
\hline
\end{tabular}

\section{Poling}

The film specimens were poled using either a conventional or a positive corona poling procedure. For the conventional poling, each sample was polarized by the application of a DC electric field $(80 \mathrm{MV} / \mathrm{m})$ at an elevated temperature $\left(\mathrm{T}_{\mathrm{g}}+5^{\circ} \mathrm{C}\right)$ in a silicone oil bath. For corona poling, a DC field of $20 \mathrm{kV}$ was applied to generate a positive corona using a single tungsten wire for four hours at $223^{\circ} \mathrm{C}$ and one hour at $212^{\circ} \mathrm{C}$. The distance between the corona tip and the specimen was approximately $30 \mathrm{~mm}$. An argon gas was maintained during the poling process. For both poling processes, the dipoles were oriented with the applied field at a temperature above $\mathrm{T}_{\mathrm{g}}$, with subsequent cooling to below $\mathrm{T}_{\mathrm{g}}$ in the presence of the applied field. The resulting remanent polarization $\left(P_{r}\right)$ is directly proportional to the material's piezoelectric response, and estimated from the following equation [4],

$$
P_{r}=\varepsilon_{0} \Delta \varepsilon E_{p}
$$

where $\varepsilon_{0}$ is the permittivity of free space $(8.854 \mathrm{pF} / \mathrm{m}), \Delta \varepsilon$ is the dielectric relaxation strength, and $E_{p}$ is the poling field.

\section{Characterization}

Degree of imidization. The glass transition temperatures $\left(\mathrm{T}_{\mathrm{g}}\right)$ of the films were measured by differential scanning calorimetry using a Shimadzu DSC-50 at a heating rate of $20^{\circ} \mathrm{C} / \mathrm{min}$ in air. The $\mathrm{T}_{\mathrm{g}}$ was taken as an inflection point of the shift of the baseline of the DSC thermogram. The degree of imidization was determined by a Nicolet FTIR spectrometer in an ATR mode using a Nicolet Contin $\mu \mathrm{m}$ IR microscope. The absorption peak at $1780 \mathrm{~cm}^{-1}$ (sym. carbonyl stretch) was used to determine the degree of imidization and that at $1500 \mathrm{~cm}^{-1}$ (ring breathing modes of the aromatic moieties) was used as an internal standard [5]. The results are presented in Table I.

Thermally stimulated current (TSC) measurement. After poling, $P_{r}$ was measured as a function of temperature. As the sample was heated through its $\mathrm{T}_{\mathrm{g}}$ at a heating rate of $1.5^{\circ} \mathrm{C} / \mathrm{min}$, the depolarization current was measured using a Keithly 6517 electrometer. The $P_{r}$ is equal to the charge per unit area, which is obtained from the data by integrating the current with respect to time and plotting it as a function of temperature.

Piezoelectric Measurement. The piezoelectric strain coefficient $\left(d_{31}\right)$ was measured using a Rheovibron DDV-II-C mechanical analyzer as a function of temperature for a range of frequencies. As the polymer is strained along the direction of applied stress, a charge Q is generated on the surface of the electrodes. A geometric factor is used to produce a geometry independent parameter, namely, surface charge density per unit applied stress.

Thermal stability Measurements. Thermal stability of the piezoelectricity in the $(\beta-\mathrm{CN})$ APB/ODPA system was carried out under both dynamic and isothermal conditions. First, the polymer sample was thermally cycled under strain by systematically increasing the maximum 
temperature from 50 to $200^{\circ} \mathrm{C}$ at a heating rate of $2^{\circ} \mathrm{C} / \mathrm{min}$. The $d_{31}$ was measured as a function of temperature for four runs, where the maximum temperature for each run was 50,100, 150, and $200^{\circ} \mathrm{C}$. The effect of the dynamic temperature cycling on the $d_{31}$ was assessed as \% retention of the piezoelectric response. Second, the as-poled samples were isothermally aged at 50, 100, 150, and $200^{\circ} \mathrm{C}$ in static air ovens. The aged samples at each temperature were tested periodically and the $P_{r}$ was measured and compared to that of the as-poled sample. The \% retention of $P_{r}$ was plotted as a function of aging temperature and time.

\section{RESULTS}

Fully-cured, conventionally poled $(\beta-C N) A P B / O D P A$ The remanent polarization of the fullycured, conventionally poled $(\beta-\mathrm{CN}) \mathrm{APB} / \mathrm{ODPA}$ was approximately $20 \mathrm{mC} / \mathrm{m}^{2}$ when poled at $80 \mathrm{MV} / \mathrm{m}$ for one hour above $\mathrm{T}_{\mathrm{g}}$. Figure 1 summarizes the results of the long-term thermal stability of this polymer. The retained $P_{r}$ after isothermal aging is presented as a function of aging time at the various temperatures. Excellent thermal stability was observed up to $100^{\circ} \mathrm{C}$, and no loss of the piezoelectric response was seen after aging at $50^{\circ} \mathrm{C}$ and $100^{\circ} \mathrm{C}$ up to $500 \mathrm{hrs}$. After aging at $150^{\circ} \mathrm{C}, 50 \%$ of the initial $P_{r}$ was retained after $100 \mathrm{hrs}$, and remained constant until 450 hrs, while at $200^{\circ} \mathrm{C}, 13 \%$ of the $P_{r}$ was retained after $100 \mathrm{hrs}$.

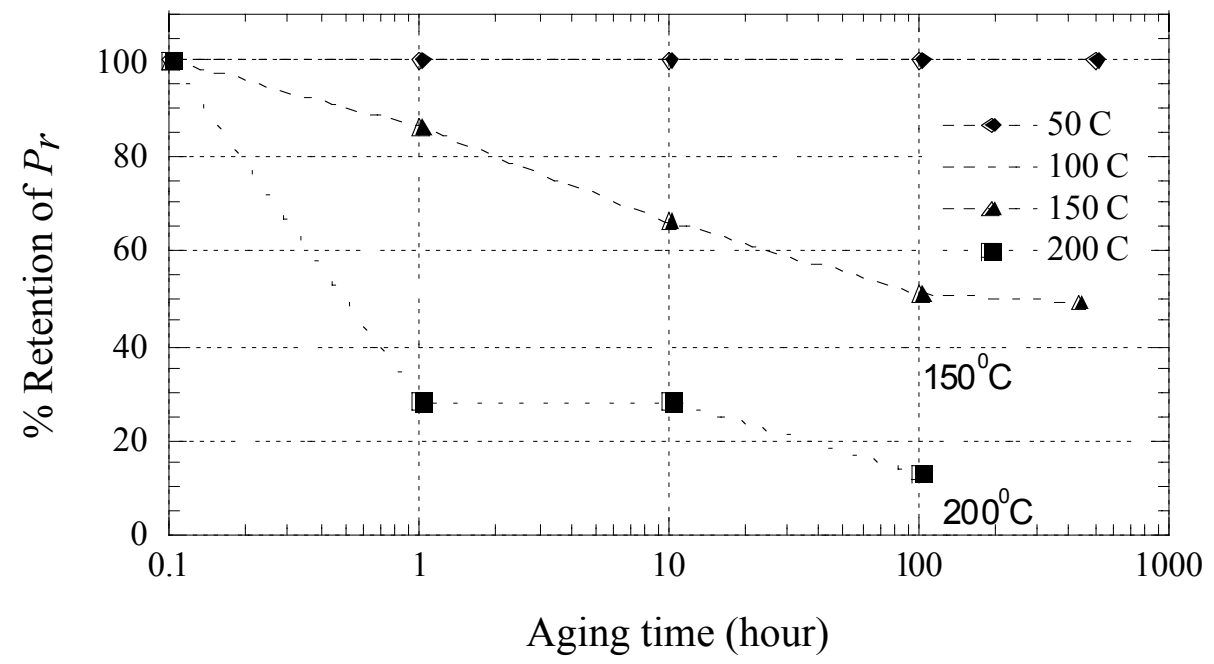

Figure 1 . Thermal stability of $P_{r}$ of $(\beta-\mathrm{CN}) \mathrm{APB} / \mathrm{ODPA}$ after aging at various temperatures.

Thermal stability of the piezoelectric strain coefficient $\left(d_{31}\right)$ under dynamic conditions was also studied and the results are shown in Figure 2 . After cycling up to $50^{\circ} \mathrm{C}$, no loss of the initial $d_{31}$ was observed on the 2 nd run, as seen in the inset of Figure 2 . The $d_{31}$ of this polymer rapidly increased with temperature above $90^{\circ}$. A $d_{31}$ value of $5 \mathrm{pC} / \mathrm{N}$ at the end of the $3 \mathrm{rd}$ run at $150^{\circ} \mathrm{C}$ and that of $10 \mathrm{pC} / \mathrm{N}$ at $200^{\circ} \mathrm{C}$ at the end of the 4 th run were obtained. These results are encouraging and portend use of these polyimides as sensors in high temperature aerospace applications. 


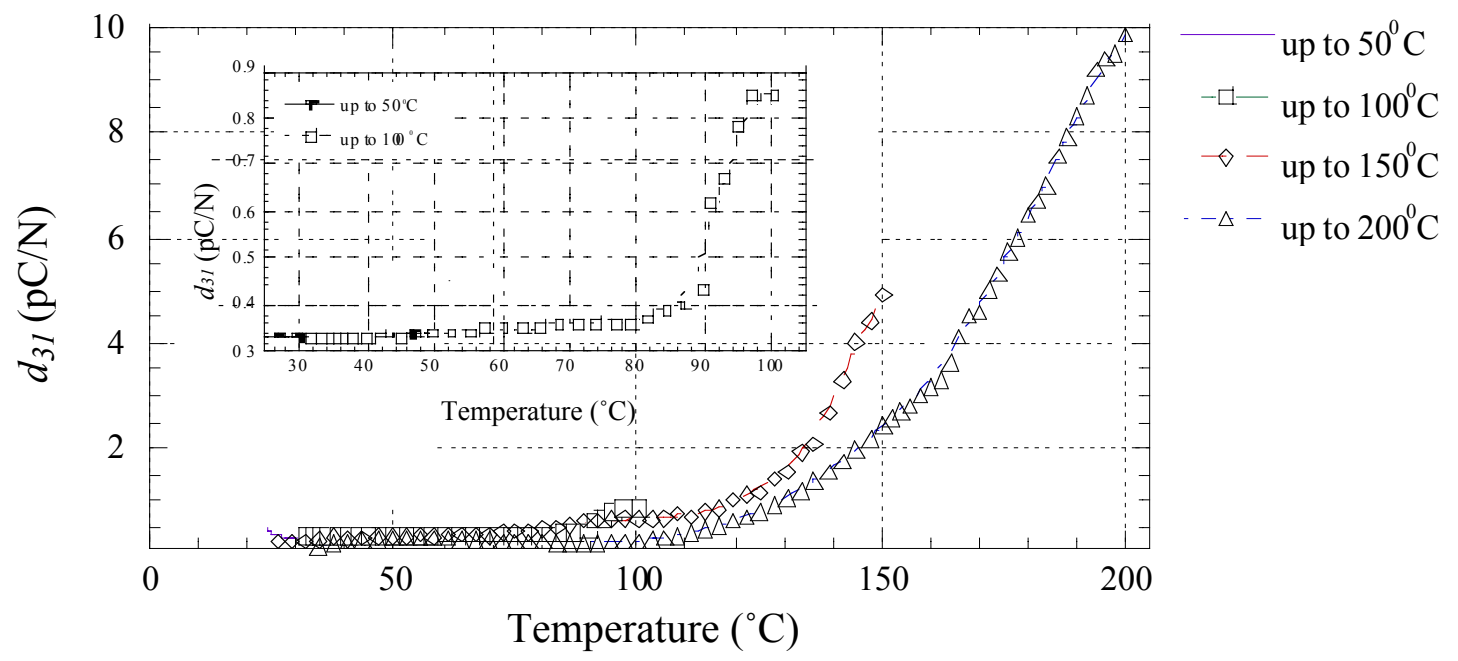

Figure 2. Dynamic stability of $\mathrm{d}_{31}$ of fully-cured, conventionally poled polyimide film $(1 \mathrm{~Hz})$.

Partially-cured, corona poled $(\beta-C N) A P B / O D P A$. A positive corona poling was used for the partially-cured polymers in an attempt to maximize the degree of dipolar orientation and minimize localized arcing during in-situ imidization and poling. The aligned polar groups should be immobilized by additional imidization and subsequent cooling in the presence of an electric field. Table I summarizes the cure cycle, $T_{g}$, and degree of imidization of the polyimides. Both the $\mathrm{T}_{\mathrm{g}}$ and the degree of imidization increased almost linearly with the final cure temperature. Thus, higher mobility of the dipoles should be expected for the polymers cured at a lower temperature. The remanent polarization of these specimens was measured, and listed in Table 1. The value of $P_{r}$ appeared higher when cured at lower temperature. Since the mobility of the molecules of the partially-cured polyimide should be much higher than that of the fully-cured one, the polar groups of the former are expected to orient parallel to the field direction more efficiently than the latter. Therefore, poling in a partially imidized state may produce a higher degree of dipole orientation than poling in a fully imidized state, thereby generating higher $P_{r}$. The P150 partially-cured polyimide exhibited six times higher $P_{r}$ than the fully-cured one under the same corona poling condition, which was greater than expected from the preliminary dielectric measurement.

Figure 3 shows an example of the $P_{r}$ of a partially-cured, corona poled $(\beta-\mathrm{CN}) \mathrm{APB} / \mathrm{ODPA}$ (P150). The partially-cured polymers tend to show broad double depolarizing current peaks during TSC measurement while the fully-cured ones depolarize with one sharp peak near $\mathrm{T}_{\mathrm{g}}$. The double peaks imply incomplete imidization during poling since the peak represent the $T_{g}$ and the dipoles poled in a partially imidized state are thermally less stable than those poled in a fully imidized state. Since the poling temperature for the partially-cured polymers was selected $5^{\circ} \mathrm{C}$ above $T_{g}$ of the fully-cured one, the dipoles aligned in the early stage (unimidized state) may not have had enough time to relax their excessive free volume during the in-situ imidization and poling process. A gradual increase of the poling temperature may be desirable to shift the lower peak maximum to the higher temperature, providing more thermal stability to the polarized dipoles.

Figures 4(a) and (b) show the normalized retention of the piezoelectric strain coefficient, $d_{31}$ of the dynamic stability tests for both fully-cured, conventionally poled and the partiallycured, corona poled ( $\beta-\mathrm{CN}) \mathrm{APB} / \mathrm{ODPA}(\mathrm{P} 150)$, respectively. In both cases, the films exhibit 


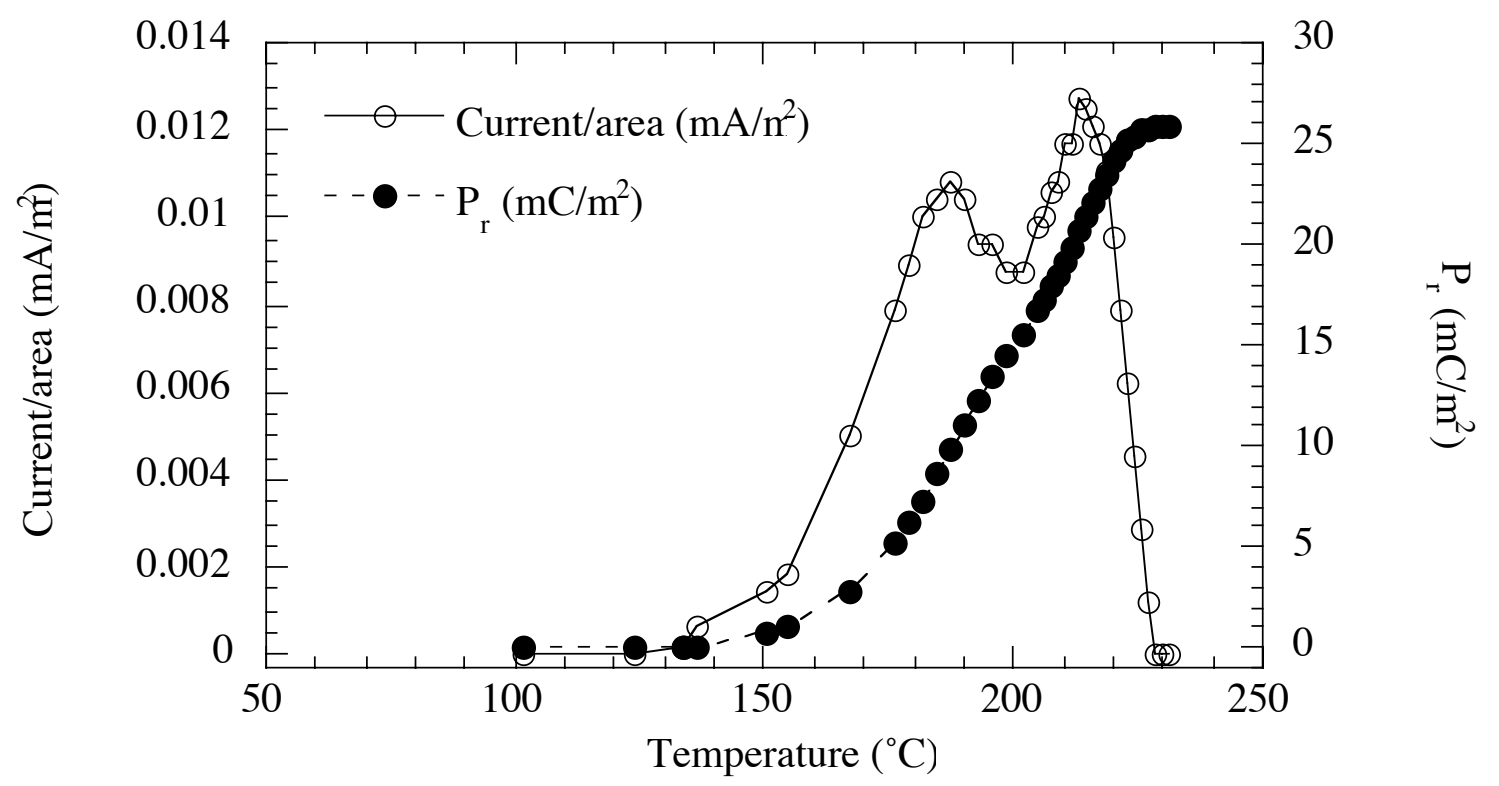

Figure 3. Thermally stimulated current measurement: current/area and $P_{r}$ versus temperature for partially-cured $(\beta-\mathrm{CN})$ APB/ODPA (P150).

very good thermal stability and virtually no loss of $d_{31}$ was observed prior to reaching $150^{\circ} \mathrm{C}$. After $150^{\circ} \mathrm{C}$, both films exhibited noticeable loss of $d_{31}$, however, the fully-cured specimen still retained about $60 \%$ of the initial value while the partially-cured one retained less than $20 \%$. The lower value of the partially-cured one may be an artifact due in part to incomplete imidization (Figure 3). Further investigations in this matter are underway. The thermal stability of the poled amorphous polyimide films did not show a significant change in the range of the measurement frequencies, from $1 \mathrm{~Hz}$ to $100 \mathrm{~Hz}$ for both poling processes.

\section{CONCLUSIONS}

Thermal stability of the amorphous piezoelectric polyimide was evaluated as a function of curing and poling conditions. The piezoelectricity of this polymer was stable under both dynamic and static thermal stimuli and statistically no loss was observed up to $100^{\circ} \mathrm{C}$. The partially-cured, corona poled polymers exhibited improved remanent polarization. Since this amorphous piezoelectric polyimide can generate a piezoelectric response at elevated temperatures, its thermal stability should be beneficial for high temperature aerospace applications.

\section{ACKNOWLEDGEMENTS}

The authors acknowledge Dr. Terry L. St. Clair of NASA-LaRC for his technical insight. We also acknowledge Mr. Bill White of Wyle Laboratories for development of the characterization measurement software. 


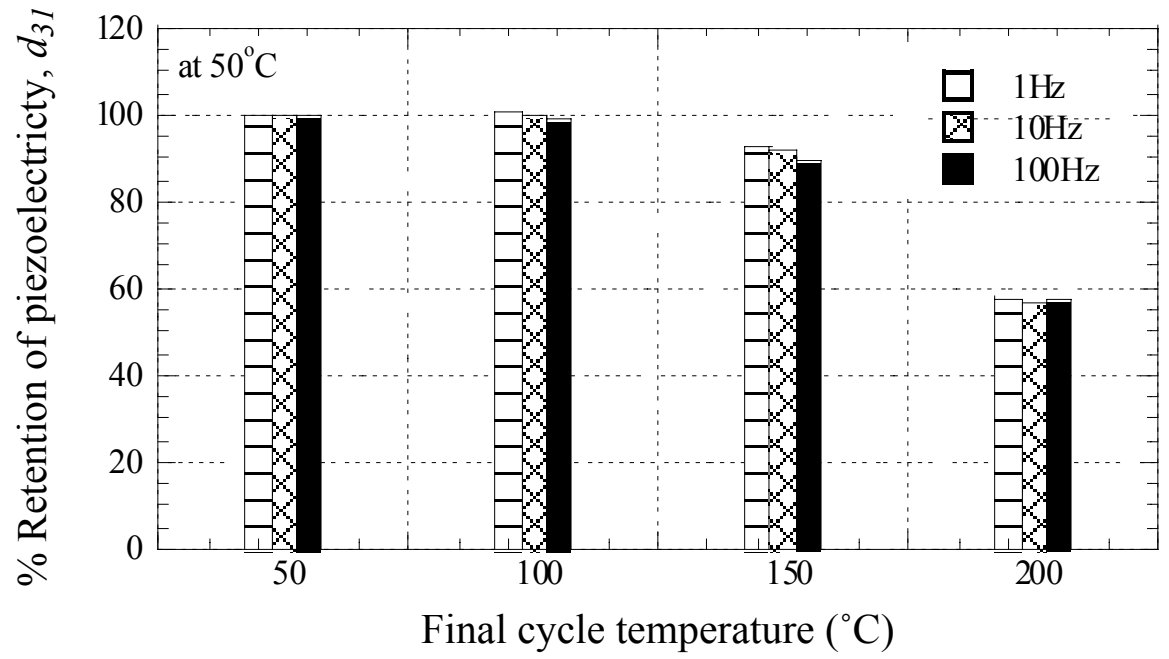

(a)

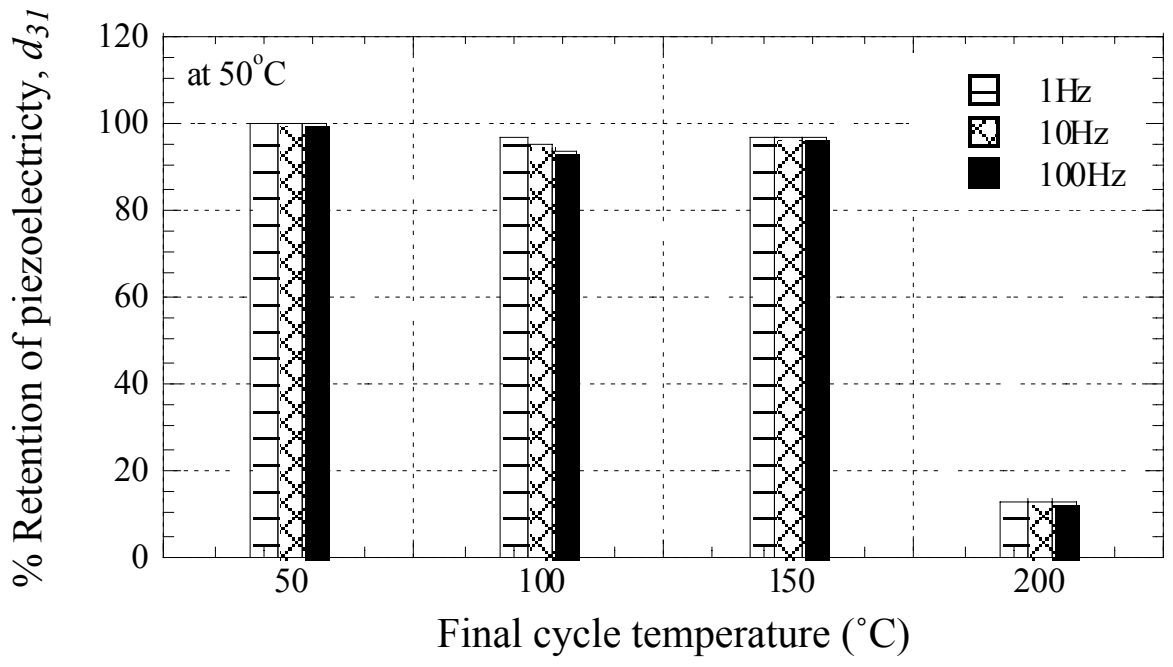

(b)

Figure 4. Percent retention of the piezoelectric strain coefficient, $\mathrm{d}_{31}$ at $50^{\circ} \mathrm{C}$ after cycling up to $50,100,150$, and $200^{\circ} \mathrm{C}$, (a) fully-cured sample (conventional poling: $80 \mathrm{MV} / \mathrm{m}, 220^{\circ} \mathrm{C}$ for $60 \mathrm{~min})$, (b) partial cured sample (corona poling)

\section{REFERENCES}

1. J.O. Simpson, S.S. Welch, and T.L. St. Clair, in Materials for Smart Systems II, edited by E.P. George, et al. (Mater. Res. Soc. Proc. 459, Boston, MA, 1997) pp. 351-356.

2. J.O. Simpson, Z. Ounaies, and C. Fay, in Materials for Smart Systems II, edited by E.P. George, et al. (Mater. Res. Soc. Proc. 459, Boston, MA 1997) pp. 59-64.

3. Z. Ounaies, C. Park, J.S. Harrison, J.G. Smith, and J. Hinkley, in Smart Structures and Materials: Electroactive Polymer Actuators and Devices, edited by Y. Bar-Cohen (Proc. SPIE 3669, Newport Beach, CA 1999) pp. 171-178.

4. B. Hilczer and J. Malecki, Electrets; Studies in Electrical and Electronic Engineering 14, Elsevier, New York, 1986, p. 19.

5. C.A. Pryde, J. Polym. Sci.: Part A: Polym. Chem. 27, p. 711 (1989). 